\title{
Do Micro-breaks Prevent Breaking of Endocrine Surgeons?
}

VNSSVAMS D Mahalakshmi ${ }^{1}$, Sapana Bothra ${ }^{2}$, Sabaretnam Mayilvaganan ${ }^{3}$, Amit Agarwal $^{4}$

\begin{abstract}
${ }^{1-4}$ Department of Endocrine Surgery, Sanjay Gandhi Postgraduate Institute of Medical Sciences, Lucknow, Uttar Pradesh, India

Corresponding Author: Sabaretnam Mayilvaganan, Department of Endocrine Surgery, Sanjay Gandhi Postgraduate Institute of Medical Sciences, Lucknow, Uttar Pradesh, India, Phone: +91 9655851510, e-mail:drretnam@gmail.com
\end{abstract}

How to cite this article: Mahalakshmi VD, Bothra S, Mayilvaganan S, Agarwal A. Do Micro-breaks Prevent Breaking of Endocrine Surgeons? World J Endoc Surg 2019;11(1):36.

Source of support: Nil

Conflict of interest: None

The surgeons are routinely subject to mental and physical stress through the course of their operating work, and endocrine surgeons, especially, with total thyroidectomy have to preserve four glands (parathyroids) and four nerves (two external branch of the superior laryngeal nerve (EBSLN) and two recurrent laryngeal nerve (RLN)) to ensure uneventful course and successful surgery without complications. We feel that during surgery for large goiters ${ }^{1}$ with high vascularity, the surgeons need patience and also need to operate with meticulous skills. In this regard, micro-breaks with targeted stretching enhance surgeons' physical function and also mental focus. ${ }^{2}$ The ergonomic strategies to mitigate pain both during open and endoscopic surgeries focus on the head and back position of surgeons. The breaks disrupt the static postures and improve physical function and mental focus. ${ }^{3}$ They serve to protect surgeons and patients.

We had implemented these micro-breaks in our unit for large goiters (five large goiters) when the surgeons and assistants took a break after the first side was operated; the operating surgeon and team had a carbohydrate drink and few neck and back stretching exercises and then operated on the other side. The knife-happy surgeon should protect himself and his assistants from the wear and tear of the surgical work and also enjoy this noble profession of curing patients. We would request other endocrine surgeons on their views as well.

\section{References}

1. Agarwal A, Agarwal S, et al. Clinicopathological profile, airway management, and outcome in huge multinodular goiters: an institutional experience from an endemic goiter region. World J Surg 2012;36(4):755-760. DOI: 10.1007/s00268-012-1447-x.

2. Park AE, Zahiri HR, et al. Intraoperative "Micro Breaks" With Targeted Stretching Enhance Surgeon Physical Function and Mental Focus: A Multicenter Cohort Study. Ann Surg 2016. [Epub ahead of print] PubMed PMID: 26863399.

3. Hallbeck MS, Lowndes BR, et al. The impact of intraoperative microbreaks with exercises on surgeons: A multi-center cohort study. Appl Ergon 2017;60:334-341. DOI: 10.1016/j.apergo.2016.12.006.

\footnotetext{
(c) The Author(s). 2019 Open Access This article is distributed under the terms of the Creative Commons Attribution 4.0 International License (https://creativecommons. org/licenses/by-nc/4.0/), which permits unrestricted use, distribution, and non-commercial reproduction in any medium, provided you give appropriate credit to the original author(s) and the source, provide a link to the Creative Commons license, and indicate if changes were made. The Creative Commons Public Domain Dedication waiver (http://creativecommons.org/publicdomain/zero/1.0/) applies to the data made available in this article, unless otherwise stated.
} 